\title{
Dissecting myocardial mechanics in patients with severe aortic stenosis: 2- dimensional vs 3-dimensional-speckle tracking echocardiography
}

Xiaojun Bi ${ }^{1,2}$, Darwin F. Yeung ${ }^{1}$, Husam M. Salah ${ }^{3}$, Maria C. Arciniegas Calle ${ }^{1}$, Jeremy J. Thaden ${ }^{1}$, Lara F. Nhola ${ }^{1}$, Hartzell V. Schaff', Sorin V. Pislaru', Patricia A. Pellikka', Alberto Pochettino', Kevin L. Greason',

Vuyisile T. Nkomo ${ }^{1}$ and Hector R. Villarraga ${ }^{1 *}$ (i)

\begin{abstract}
Background: Aortic stenosis (AS) causes left ventricular (LV) pressure overload, leading to adverse LV remodeling and dysfunction. Identifying early subclinical markers of LV dysfunction in patients with significant AS is critical as this could provide support for earlier intervention, which may result in improved long-term outcomes. We therefore examined the impact of severe AS and its consequent increase in LV afterload on myocardial deformation and rotational mechanics by 2-dimensional (2D) and 3-dimensional (3D) speckle-tracking echocardiography.

Methods: We prospectively measured various strain parameters in 168 patients ( $42 \%$ female, mean age $72 \pm 12$ years) with severe AS and LV ejection fraction (EF) $\geq 50 \%$, and compared them to normal values found in literature. 2D and 3D images were analyzed for global longitudinal strain (GLS), global circumferential strain (GCS), global radial strain (GRS), basal rotation, apical rotation, and peak systolic twist. We further assessed the degree of concordance between 2D and 3D strain, and examined their association with measures of LV preload and afterload.

Results: Patients with severe AS exhibited significantly lower GLS and GRS but higher GCS, apical rotation, and twist by $2 \mathrm{D}$ and $3 \mathrm{D}$ echocardiography compared with published normal values $(P=0.003$ for 3D twist, $P<0.001$ for all others). Agreement between 2D- and 3D-GLS by concordance correlation coefficient was 0.49 ( $95 \%$ confidence interval: 0.39-0.57). GLS was correlated with valvulo-arterial impedance, a measure of LV afterload $(r=0.34, p<0.001$ and $r=0.23, p=0.003$, respectively).
\end{abstract}

Conclusion: Patients with severe AS demonstrated lower-than-normal GLS and GRS but appear to compensate with higher-than-normal GCS, apical rotation, and twist in order to maintain a preserved LVEF. GLS showed a modest correlation with valvulo-arterial impedance.

Keywords: Aortic stenosis, Speckle-tracking echocardiography, Strain, Myocardial mechanics

\footnotetext{
*Correspondence: villarraga.hector@mayo.edu

'Department of Cardiovascular Diseases, Mayo Clinic, 200 First St SW,

Rochester, MN 55905, USA

Full list of author information is available at the end of the article
}

(c) The Author(s). 2020 Open Access This article is distributed under the terms of the Creative Commons Attribution 4.0 International License (http://creativecommons.org/licenses/by/4.0/), which permits unrestricted use, distribution, and reproduction in any medium, provided you give appropriate credit to the original author(s) and the source, provide a link to the Creative Commons license, and indicate if changes were made. The Creative Commons Public Domain Dedication waiver (http://creativecommons.org/publicdomain/zero/1.0/) applies to the data made available in this article, unless otherwise stated. 


\section{Background}

Aortic stenosis (AS) is the most common native valve disease and is characterized by left ventricular (LV) pressure overload. In patients with AS, the LV faces two afterloads: one from the valvular obstruction itself and the other from reduced systemic arterial compliance $[1$, 2]. Progressive increases in afterload lead to LV remodeling and a change in coronary flow reserve. These alterations can cause subendocardial ischemia and fibrosis and may gradually affect LV systolic function [3, 4]. LV ejection fraction (LVEF) is the most important conventional parameter used to assess LV myocardial function. However, a decrease in LVEF usually occurs at an end stage of severe AS.

Global longitudinal strain (GLS) by 2-dimensional (2D) speckle-tracking echocardiography can be used to detect early LV systolic dysfunction and has been proposed as a more sensitive way to detect a decline in LV function in patients with AS [5-11]. However, the process of ventricular contraction is complex, as relaxation occurs in three dimensions. Therefore, 3-dimensional (3D) speckletracking echocardiography could provide a more precise representation of myocardial deformation [12]. New insights into LV remodeling and myocardial deformation could potentially improve our ability to identify patients with aortic stenosis who are at highest risk for adverse remodeling or early LV dysfunction [13-18]. However, few studies have comprehensively characterized myocardial deformation in patients with severe aortic stenosis by $3 \mathrm{D}$ speckle-tracking echocardiography $[18,19]$.

The objectives of this prospective study were to: 1) to determine how myocardial deformation is affected in patients with severe AS and preserved LVEF compared with normal values found in literature; 2) to compare 2D to $3 \mathrm{D}$ echocardiographic measures of LV myocardial deformation in patients with severe AS; and 3) to characterize the relationship between LV preload and afterload and myocardial deformation.

\section{Methods}

\section{Study population}

We prospectively recruited 181 patients with severe AS, defined as a mean gradient $>40 \mathrm{mmHg}$ or an aortic valve area $<1.0 \mathrm{~cm}^{2}$, and who had a preserved LVEF, defined as $\geq 50 \%$, on transthoracic echocardiography. The study was performed at Mayo Clinic, Rochester, Minnesota from November 1, 2014 to August 31, 2015. Patients were excluded if they were $<18$ years of age; if they had an irregular rhythm; if they had moderate or greater aortic or mitral regurgitation; or if image quality was inadequate. The final analysis included 168 patients. This study was approved by the Mayo Clinic Institutional Review Board, and all patients gave informed consent to participate.

\section{Image acquisition and analysis}

Each patient underwent a standard 2D and a real-time 3D transthoracic echocardiogram in the left lateral decubitus position, using commercially available equipment (IE33 and EPIQ7, Philips Medical Systems, Andover, Massachusetts) with a fully sampled matrix-array transducer (X51). Vital signs were measured in all patients immediately before the echocardiographic examination. Studies were performed by an experienced cardiologist (X.B.). 3D fullvolume images were acquired from the apical window with a 6-beat acquisition, a high volume rate (average, $\geq 30$ volumes/s), and full coverage of the entire LV by the pyramidal volume. Patients were instructed to hold their breath during image acquisition. Images were optimized for endocardial border visualization by adjustment of overall gain, compression, and time gain compensation before acquisitions. The acquired 2D images and 3D fullvolume images were analyzed offline with TomTec 4D Echo software, version 4.6 (TomTec Imaging Systems, Image Arena, Unterschleissheim, Germany).

For 2D echocardiography, the standard 2D, M-mode, and Doppler measurements were obtained in accordance with guidelines from the American Society of Echocardiography [20]. LV end-diastolic volume (LVEDV), end-systolic volume (LVESV), and ejection fraction (LVEF) were measured manually by using the Simpson's biplane method. Three standard apical views (4-chamber, long-axis, and 2chamber) were obtained for the assessment of global longitudinal strain (GLS) and three parasternal short-axis views (basal, mid, and apical levels) were obtained for the assessment of global circumferential strain (GCS), global radial strain (GRS), LV apical peak systolic rotation, LV basal peak systolic rotation, and peak systolic twist.

For 3D echocardiography, three standard apical views were automatically extracted from the 3D full-volume data sets. The mitral annulus and the LV apex were manually selected as the landmarks to initialize the LV boundaries. Then, the $3 \mathrm{D}$ endocardial surface was automatically reconstructed at end-diastole and end-systole. The endocardial surface reconstruction was manually adjusted, as necessary, and the papillary muscles were included as part of the LV cavity. Subsequently, 3D speckle-tracking was automatically characterized. The software provided longitudinal, radial, circumferential, and principal tangential strain time curves for the 16 segments and peak global strain, as well as averaged peak strain at three LV levels (basal, mid-ventricular, and apical) (Fig. 1).

To measure afterload, total arterial stiffness (TAS) was measured by the formula: TAS $=$ pulse pressure/stroke volume (SV); total arterial compliance (TAC) was measured by the formula: $\mathrm{TAC}=\mathrm{SV} /$ pulse pressure; effective arterial elastance (EAE) was measured by the formula: $\mathrm{EAE}=$ end systolic pressure/SV; systemic vascular 


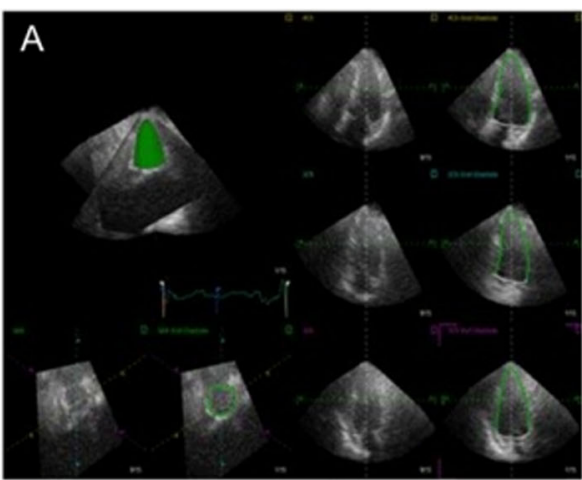

LVED

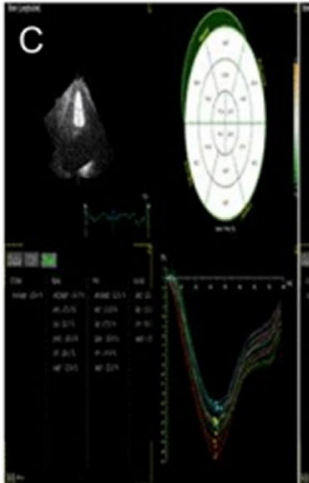

GLS

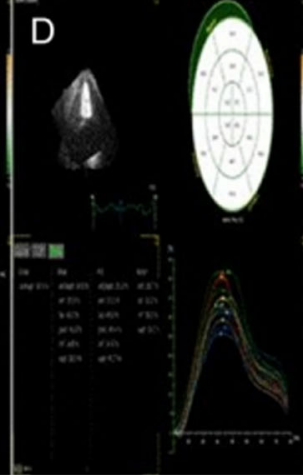

GRS

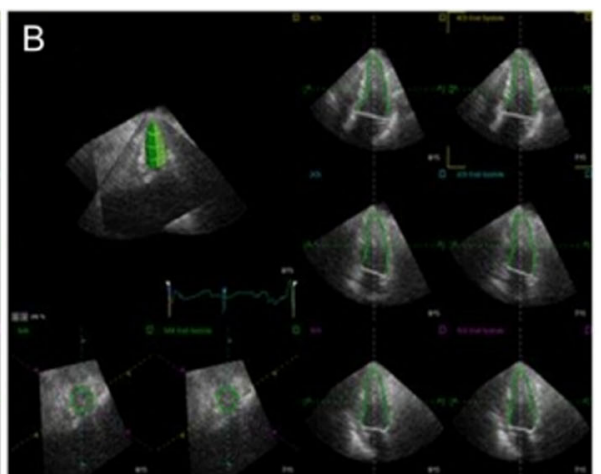

LVSD

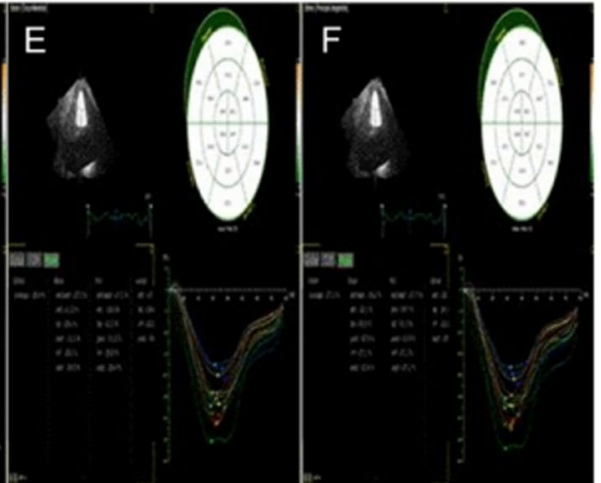

GCS
GPTS

Fig. 1 Three-dimensional (3D) speckle-tracking with TomTec 4D Echo Software (TomTec Imaging Systems, Image Arena, Unterschleissheim, Germany). Standard three apical views and one short-axis view of the left ventricle (LV) were automatically extracted from the 3D full-volume data sets. The 3D endocardial surface was automatically reconstructed at LV end-diastole (LVED) (a) and LV end-systole (LVSD) (b). The software provided global longitudinal strain (GLS) (c), global radial strain (GRS) (d), global circumferential strain (GCS) (e), and global principal tangential strain (GPTS) (f) time curves in 16 segments as well as peak global strain and averaged peak strain at three LV levels (basal, mid, and apical)

resistance (SVR) was measured by the formula: SVR= $[80 \times($ mean arterial pressure - right atrial pressure $)] /$ cardiac output; systemic vascular resistance index (SVRI) was measured by the formula: SVRI $=[80 \times($ mean arterial pressure - right atrial pressure)]/cardiac index [21]. Briand et al. [1] proposed a simple index to measure global LV afterload called the valvulo-arterial impedance $\left(Z_{\mathrm{va}}\right)$, which can be calculated by the formula: $Z_{\mathrm{va}}=(\mathrm{SAP}$ $\left.+\mathrm{MG}_{\text {net }}\right) / \mathrm{SVI}$, where SAP is the systolic arterial pressure, $M G_{\text {net }}$ is the mean net pressure gradient transvalvular pressure, and SVI is the stroke volume index. Therefore, $Z_{\mathrm{va}}$ represents the valvular and arterial factors that oppose ventricular systole by absorbing the mechanical energy developed by the left ventricle [22].

Intra- and inter-observer variability of 2D and 3D speckletracking measurements

For reproducibility of $2 \mathrm{D}$ - and 3D-speckle-tracking echocardiographic measurements of deformation parameters, 20 patients were randomly selected and reanalyzed by the same observer to determine the intra-observer agreement and by a second experienced echocardiographer, who was blinded to the initial results, to determine the interobserver agreement. Both measurements were obtained with the intra-class correlation coefficient (ICC).

\section{Statistical analysis}

Data were presented as mean \pm standard deviation (SD) for continuous variables and as number (percentages) for categorical variables. The various strain parameters measured in this study were compared to those of normal healthy patients previously published in literature including two meta-analyses with pooled data from $>2000$ patients each for both the 2D and 3D global strain measurements [2325]. Agreement between parameters in $2 \mathrm{D}$ and $3 \mathrm{D}$ were assessed using the concordance correlation coefficient (CCC) with $95 \%$ confidence interval (CI). Associations between two continuous variables were measured using the Pearson $(r)$ or Spearman correlation $(\rho)$ coefficient. Variability between the two sets of measurements was reported as the mean difference \pm SD and the ICC with 95\% CI. Means for 2D and 3D GLS, GCS, and GRS were compared with the one-sample $t$-test using reference values obtained from two large meta-analyses [23, 24]. All other means 
were compared with the two-sample $t$-test. Data were analyzed with JMP 10.0 software (SAS Institute Inc., Cary, North Carolina) and MedCalc statistical software, version 11.4.1.0 (MedCalc Software, Ostend, Belgium). A $P$ value $<0.05$ was considered statistically significant.

\section{Results}

\section{Clinical and echocardiographic characteristics}

Table 1 lists the clinical characteristics of cohort patients with severe AS and preserved LVEF. A total of 168 patients were included in the study, of whom, 70 (42\%) were female with a mean age of $72 \pm 12$ years. Hypertension and coronary artery disease were present in 80 and $49 \%$ of patients respectively.

Echocardiographic characteristics of cohort patients with severe AS and preserved LVEF are listed in Table 2. 2D measurements were available for all 168 patients and 3D measurements were available for 165 of them. Measures of preload in the cohort patients included an LV end-diastolic dimension of $48 \pm 6 \mathrm{~mm}$ and an indexed LVEDV of $63 \pm 20 \mathrm{~mL} / \mathrm{m}^{2}$ while the calculated indices of LV afterload were as follows: total arterial stiffness, $0.8 \pm$ $0.3 \mathrm{mmHg} / \mathrm{mL}$; total arterial compliance, $1.5 \pm 0.7 \mathrm{~mL} /$ $\mathrm{mm} \mathrm{Hg}$; systemic vascular resistance, $1368 \pm 438 \mathrm{~mL} /$ $\mathrm{mm} \mathrm{Hg} / \mathrm{m}^{2}$; systemic vascular resistance index, $2628 \pm$ 788 dynes $\bullet \mathrm{s} / \mathrm{cm}^{-5}$; and Zva, $3.7 \pm 0.7 \mathrm{mmHg} / \mathrm{mL} / \mathrm{m}^{2}$.

\section{Parameters of speckle-tracking strain imaging in 2D and 3D}

The parameters of 2D and 3D speckle-tracking strain for both groups are shown in Table 3. For both 2D and 3D

Table 1 Clinical characteristics $(N=168)$

\begin{tabular}{ll}
\hline Variable & Value \\
\hline Demographics & $72 \pm 12$ \\
Age $(y)$ & $70(42)$ \\
Female & $1.95 \pm 0.26$ \\
Body surface area $\left(\mathrm{m}^{2}\right)$ & \\
Functional status & $57 / 57 / 45 / 9$ \\
New York Heart Association I/II/II/IV & \\
Medical history & $82(49)$ \\
Coronary artery disease & $55(33)$ \\
Diabetes mellitus & $134(80)$ \\
Hypertension & $113(67)$ \\
Dyslipidemia & $20(12)$ \\
Current tobacco use & \\
Physical examination & $67 \pm 12$ \\
Heart rate (beats/min) & $129 \pm 18$ \\
Systolic blood pressure $(\mathrm{mm} \mathrm{Hg})$ & $70 \pm 10$ \\
Diastolic blood pressure $(\mathrm{mm} \mathrm{Hg})$ &
\end{tabular}

Data expressed as mean \pm standard deviation or $\mathrm{n}(\%)$
Table 2 Echocardiographic features

\begin{tabular}{|c|c|}
\hline Variable & Value \\
\hline \multicolumn{2}{|l|}{ 2D measurements $(N=168)$} \\
\hline LV end-diastolic diameter (mm) & $48 \pm 6$ \\
\hline LV end-systolic diameter (mm) & $30 \pm 5$ \\
\hline Interventricular septum thickness (mm) & $12 \pm 2$ \\
\hline Posterior wall thickness (mm) & $11 \pm 2$ \\
\hline LV mass index (g/m2) & $109 \pm 34$ \\
\hline LV end-diastolic volume index $\left(\mathrm{mL} / \mathrm{m}^{2}\right)$ & $63 \pm 20$ \\
\hline LV end-systolic volume index $\left(\mathrm{mL} / \mathrm{m}^{2}\right)$ & $24 \pm 11$ \\
\hline LV stroke volume index $\left(\mathrm{mL} / \mathrm{m}^{2}\right)$ & $40 \pm 10$ \\
\hline LV ejection fraction (\%) & $63 \pm 6$ \\
\hline E velocity $(\mathrm{cm} / \mathrm{s})$ & $96 \pm 42$ \\
\hline A velocity $(\mathrm{cm} / \mathrm{s})$ & $104 \pm 36$ \\
\hline E/A ratio & $0.9 \pm 0.4$ \\
\hline Septal e' velocity (cm/s) & $5.4 \pm 1.7$ \\
\hline Septal E/e' ratio & $17.3 \pm 7.5$ \\
\hline Aortic valve peak velocity $(\mathrm{m} / \mathrm{s})$ & $4.4 \pm 0.5$ \\
\hline Aortic valve mean gradient (mm Hg) & $49 \pm 12$ \\
\hline Aortic valve area $\left(\mathrm{cm}^{2}\right)$ & $0.89 \pm 0.16$ \\
\hline Aortic valve area index $\left(\mathrm{cm}^{2} / \mathrm{m}^{2}\right)$ & $0.46 \pm 0.07$ \\
\hline Total arterial stiffness ( $\mathrm{mm} \mathrm{Hg} / \mathrm{mL}$ ) & $0.8 \pm 0.3$ \\
\hline Total arterial compliance (mL/mm Hg) & $1.5 \pm 0.7$ \\
\hline Systemic vascular resistance $\left(\mathrm{mL} / \mathrm{mm} \mathrm{Hg} / \mathrm{m}^{2}\right)$ & $1368 \pm 438$ \\
\hline Systemic vascular resistance index $\left(\right.$ dynes $• s / \mathrm{cm}^{-5}$ ) & $2628 \pm 788$ \\
\hline Valvulo-arterial impedance $\left(Z_{v a}\right)\left(\mathrm{mm} \mathrm{Hg} / \mathrm{mL} / \mathrm{m}^{2}\right)$ & $3.7 \pm 0.7$ \\
\hline \multicolumn{2}{|l|}{ 3D measurements $(N=165)$} \\
\hline LV end-diastolic volume index $\left(\mathrm{mL} / \mathrm{m}^{2}\right)$ & $62 \pm 16$ \\
\hline LV end-systolic volume index $\left(\mathrm{mL} / \mathrm{m}^{2}\right)$ & $24 \pm 9$ \\
\hline LV stroke volume index $\left(\mathrm{mL} / \mathrm{m}^{2}\right)$ & $38 \pm 9$ \\
\hline LV ejection fraction (\%) & $61 \pm 5$ \\
\hline
\end{tabular}

Data expressed as mean \pm standard deviation

Abbreviations: 2D 2-dimensional, LV Left ventricular, 3D 3-dimensional

images, cohort patients with severe AS and preserved LVEF demonstrated lower GLS and GRS $(P<0.0001$ for all) and higher apical rotation and peak systolic twist $(P=0.003$ for $3 \mathrm{D}$ twist, $P<0.0001$ otherwise) compared with those of healthy subjects previously published in literature. There was no significant difference in 2D and $3 \mathrm{D}$ basal rotation in patients with severe AS compared with normal values.

\section{Comparison of 2D and 3D echocardiographic measurements}

The agreement of echocardiographic data between 2D and 3D images is shown in Figs. 2 and 3. A relatively fair level of agreement existed between 2D and 3D GLS $(\mathrm{CCC}=0.49,95 \%$ CI $0.39-0.57$; and $\rho=0.54, P<0.0001)$ 
Table 3 Myocardial mechanics

\begin{tabular}{llll}
\hline Parameter & Study cohort & Reference values & $P$ value \\
\hline 2D measurements $(N=168)$ & & \\
GLS (\%) & $-16.2 \pm 2.1$ & $-19.7(-20.4,-18.9)^{\mathrm{a}}$ & $<0.0001$ \\
GCS (\%) & $-27.4 \pm 4.6$ & $-23.3(-24.6,-22.1)^{\mathrm{a}}$ & $<0.0001$ \\
GRS (\%) & $37.5 \pm 8.2$ & $47.3(43.6,51.0)^{\mathrm{a}}$ & $<0.0001$ \\
Basal rotation ( $\left.{ }^{\circ}\right)$ & $-7.8 \pm 2.2$ & $-7.5 \pm 5.4^{\mathrm{b}}$ & 0.06 \\
Apical rotation $\left(^{\circ}\right)$ & $10.7 \pm 4.0$ & $6.3 \pm 3.5^{\mathrm{b}}$ & $<0.0001$ \\
Twist $\left(^{\circ}\right)$ & $18.5 \pm 4.7$ & $13.4 \pm 8.2^{\mathrm{b}}$ & $<0.0001$ \\
3D measurements $(N=165)$ & & \\
GLS (\%) & $-14.5 \pm 1.9$ & $-19.1(-18.2,19.9)^{\mathrm{c}}$ & $<0.0001$ \\
GCS (\%) & $-30.5 \pm 7.1$ & $-22.4(-21.0,-23.9)^{\mathrm{c}}$ & $<0.0001$ \\
GRS (\%) & $41.6 \pm 9.8$ & $47.5(41.5,53.5)^{\mathrm{c}}$ & $<0.0001$ \\
Twist $\left({ }^{\circ}\right)$ & $13.7 \pm 7.0$ & $10.2 \pm 7.6^{\mathrm{b}}$ & 0.003 \\
\hline
\end{tabular}

Data are expressed as mean \pm standard deviation or mean $(95 \%$ confidence interval)

Abbreviations: 2D 2-dimensional, 3D 3-dimensional, GLS Global longitudinal strain, GCS Global circumferential strain, GRS Global radial strain

aYingchoncharoen et al. [23]

${ }^{\mathrm{b}}$ Andrade et al. [24]

'Truong et al. [25]

for patients with severe AS. The agreement between 2D and $3 \mathrm{D}$ images was poor for $\mathrm{GCS}(\mathrm{CCC}=0.29,95 \% \mathrm{CI}$ $0.16-0.41$ and $\rho=0.23, P<0.002])$, and GRS $(\mathrm{CCC}=$
$0.10,95 \% \mathrm{CI}-0.04-0.23$ and $\rho=-0.2, P<0.02$ ), and peak systolic twist $(C C C=0.11,95 \%$ CI $0-0.21)$. An excellent level of agreement existed between 2D and 3D LVEDV (CCC =0.89, 95\% CI 0.85-0.91) (Fig. 3). A fair level of agreement existed between $2 \mathrm{D}$ and 3D LVEF $(\mathrm{CCC}=0.51,95 \%$ CI 0.39-0.61).

\section{Relationship between myocardial deformation and measures of preload and afterload}

GLS by $2 \mathrm{D}$ and $3 \mathrm{D}$ was correlated with $\mathrm{Z}_{\mathrm{va}}(r=0.34, p<$ $0.001 ; r=0.23, p=0.003$, respectively). The other deformation parameters, including apical rotation and peak systolic twist in 2D and 3D showed no correlation with $Z_{\mathrm{va}}$. Among all of the indexes of afterload, only $Z_{\mathrm{va}}$ demonstrated the modest correlation with 2D and 3D GLS. Among the parameters of preload, indexed LVEDV demonstrated a weak correlation with $2 \mathrm{D}$ and 3D GLS (2D GLS, $r=0.14, P=0.04$; 3D GLS, $r=0.22, P<0.001$ ).

\section{Intra- and inter-observer variability}

Table 4 shows the results of the intra-observer and inter-observer variability for 2D and 3D speckle-tracking echocardiography measurements. Our results showed excellent correlation, with ICC values ranging from 0.84 to 0.95 and a mean of 0.90 .
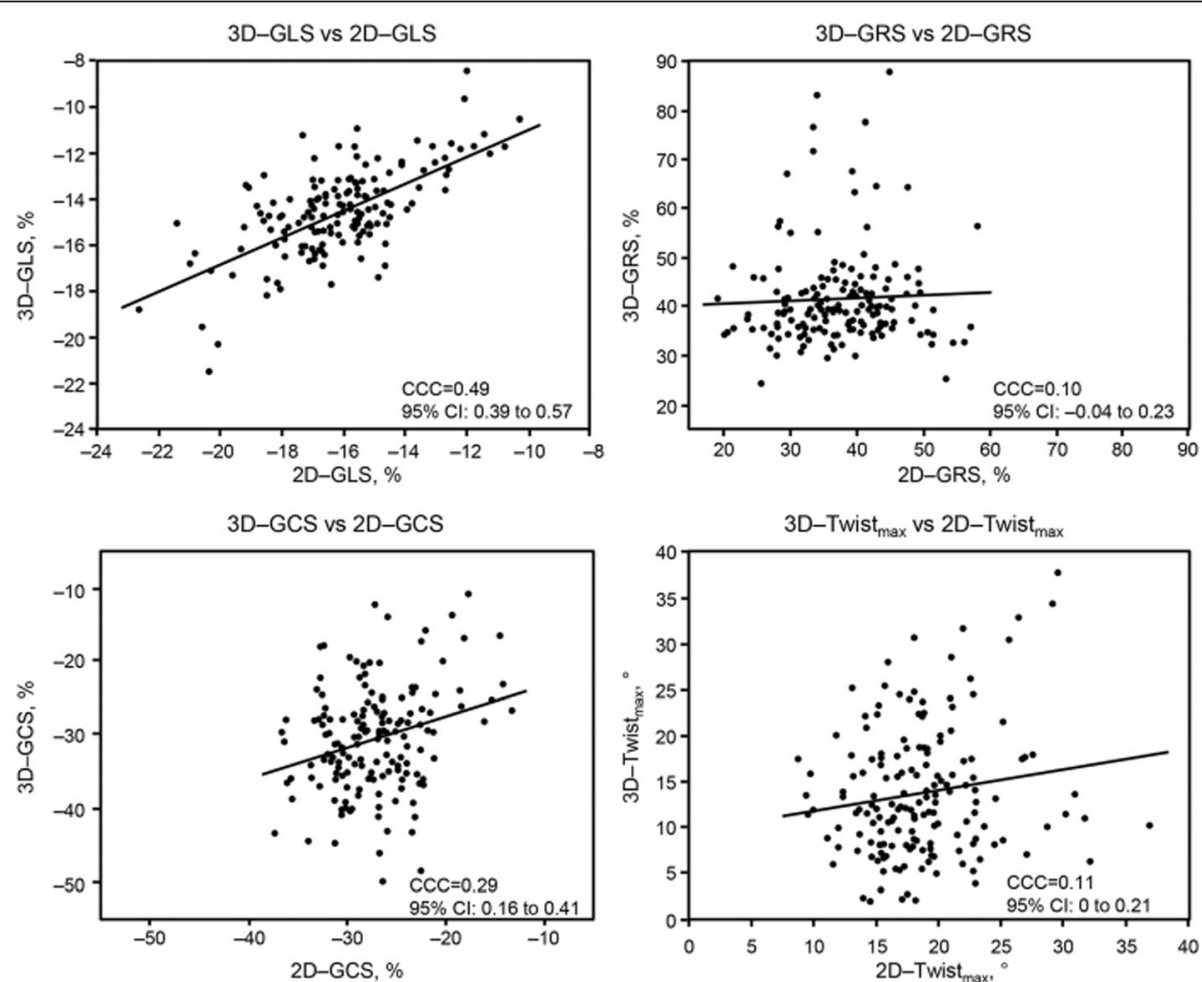

Fig. 2 Agreement between 2-dimensional (2D) and 3-dimensional (3D) strain parameters of the left ventricle. Abbreviations: GLS, global longitudinal strain; 2D-GRS, global radial strain; GCS, global circumferential strain; Twist max, peak systolic twist; CCC, concordance correlation coefficient; $\mathrm{Cl}$, confidence interval 

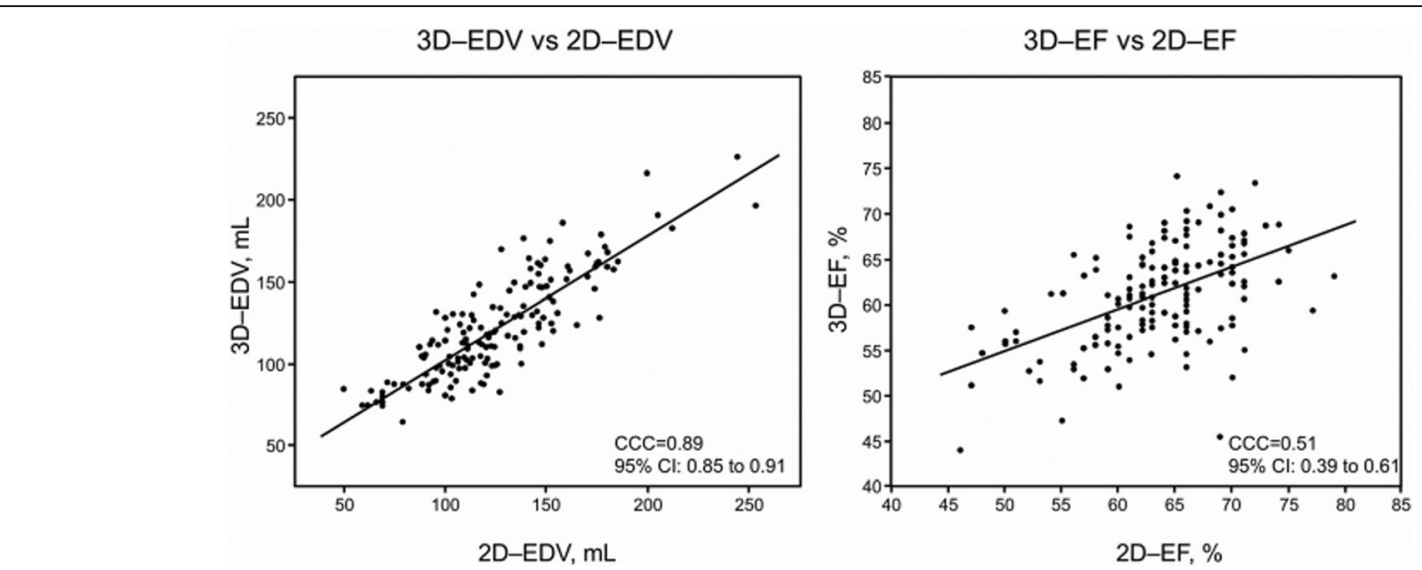

Fig. 3 Agreement between conventional 2-dimensional (2D) and 3-dimensional (3D) echocardiographic parameters of the left ventricle. Abbreviations: EDV, end-diastolic volume; EF; ejection fraction; CCC, concordance correlation coefficient; $\mathrm{Cl}$, confidence interval

\section{Discussion}

Our study provides the most comprehensive simultaneous $2 \mathrm{D}$ and 3D characterization of myocardial mechanics to date in patients with severe AS and preserved LVEF. These patients demonstrated subclinical LV systolic dysfunction in the form of reduced GLS and GRS along with concomitant increases in GCS, apical rotation, and peak systolic twist, which may represent compensatory mechanisms to maintain the LVEF within normal limits. We were able to demonstrate these changes in mechanics by both $2 \mathrm{D}$ and $3 \mathrm{D}$ speckletracking echocardiography. Furthermore, GLS showed a weak correlation with indexed LVEDV, a measure of preload, and a modest correlation with valvulo-arterial impedance, a measure of afterload.

Characterization of myocardial mechanics through the echocardiographic assessment of myocardial deformation, or strain, can provide a more thorough representation of LV contractile function [26]. Through the measurement

Table 4 Intra- and inter-observer variability $(N=20)$

\begin{tabular}{|c|c|c|c|c|}
\hline \multirow[t]{2}{*}{ Measurement } & \multicolumn{2}{|l|}{ Intra-observer } & \multicolumn{2}{|l|}{ Inter-observer } \\
\hline & Difference & ICC & Difference & ICC \\
\hline \multicolumn{5}{|l|}{$2 \mathrm{D}$} \\
\hline GLS (\%) & $-0.08 \pm 0.17$ & 0.93 & $0.40 \pm 0.95$ & 0.88 \\
\hline GRS (\%) & $-0.12 \pm 1.17$ & 0.85 & $-0.15 \pm 4.70$ & 0.86 \\
\hline GCS (\%) & $-0.33 \pm 2.59$ & 0.92 & $1.01 \pm 2.88$ & 0.90 \\
\hline Twist $\left({ }^{\circ}\right)$ & $0.23 \pm 2.69$ & 0.86 & $0.06 \pm 1.92$ & 0.93 \\
\hline \multicolumn{5}{|l|}{$3 \mathrm{D}$} \\
\hline GLS (\%) & $0.40 \pm 0.78$ & 0.95 & $-0.08 \pm 1.46$ & 0.84 \\
\hline GRS (\%) & $0.85 \pm 0.89$ & 0.87 & $1.38 \pm 3.81$ & 0.82 \\
\hline GCS (\%) & $0.25 \pm 3.72$ & 0.90 & $0.67 \pm 3.48$ & 0.89 \\
\hline Twist $\left({ }^{\circ}\right)$ & $-0.07 \pm 0.76$ & 0.87 & $0.01 \pm 0.65$ & 0.89 \\
\hline
\end{tabular}

Abbreviations: ICC Intraclass correlation coefficient, 2D 2-dimensional, GLS Global longitudinal strain, GCS Global circumferential strain, GRS Global radial strain, 3D 3-dimensional of strain, changes in LV myocardial contraction can be detected in three directions: longitudinal strain reflects contraction of the longitudinally arranged endocardial and epicardial fibers; circumferential strain represents contraction of the circumferentially arranged mid-layer fibers; and radial strain denotes contraction of the full-thickness LV wall. In the presence of subendocardial ischemia, longitudinal strain is generally the first to decrease, due to the longitudinal arrangement of endocardial fibers [27]. A subsequent increase in circumferential strain can compensate for declines in longitudinal strain to maintain normal radial strain and LVEF.

Patients with severe AS and preserved LVEF in our cohort exhibited lower-than-normal GLS, a finding consistent with that found in several prior studies [5-19]. In patients with severe AS, the increased afterload may lead to left ventricular hypertrophy, decreased coronary perfusion, subendocardial ischemia, and eventually myocardial fibrosis $[3,4]$. The endocardium is usually the most vulnerable to increased wall stress and stress-induced ischemia with LV pressure overload, resulting in impairment in longitudinal strain before others [28]. Indeed, layer-specific strain analysis reveals a reduction in GLS limited to the subendocardial layer even in patients with mild AS, which worsened with progression to involve the other layers with increasing severity of AS [28].

Reduced GLS was accompanied by increased GCS in our cohort of patients with severe AS and preserved LVEF, in keeping with the tendency for circumferential strain to increase in order to maintain a normal LVEF [27]. However, while GLS has consistently been shown to be low in patients with severe AS, prior studies have demonstrated either a decrease $[5,10,29]$ or an increase in GCS $[10,30]$ in these patients. Of note, patients in those previous studies with a reduced GCS tended to have a reduced LVEF whereas those with an elevated GCS tended to have a preserved LVEF. It is possible that 
these patients initially develop increases in GCS to counter reductions in GLS and maintain a normal LVEF but then eventually experience reductions in GCS and as a result LVEF as well.

In addition to increases in circumferential strain, apical rotation and peak systolic twist were also significantly higher than normal in our cohort of patients with severe AS and preserved LVEF, which is consistent with prior findings $[7,10,11,29,31]$. Prior studies have reported good correlations between LV twist derived from 2D speckle-tracking echocardiography and magnetic resonance imaging $[32,33]$. The counter-coiled helical arrangement of subendocardial and subepicardial fibers generates an LV twist that has been proven to be fundamental to LV contraction and therefore $\operatorname{LVEF}[34,35]$. Similar to circumferential strain, increases in apical rotation and twist may thus also serve to compensate for the declines in GLS in order to maintain normal LVEF and cardiac output. In fact, one prior study showed that patients with lower LVEF values tended to exhibit higher degrees of apical rotation [10].

Few prior studies have assessed changes in radial strain and basal rotation in patients with severe AS $[5,7,11]$. In our cohort, patients similarly demonstrated lower GRS [5] and no difference in basal rotation $[7,11]$ compared with normal values. Unlike all prior studies, our study represents to our knowledge the first to characterize longitudinal, circumferential, and basal strain, along with apical rotation, basal rotation, and twist within the same cohort of patients with severe AS using both 2D and 3D speckletracking echocardiography.

In patients with degenerative AS, arterial compliance is frequently reduced, which contributes to increased afterload and decreased LV function. Hence, the LV is often subjected to a double afterload from valvular obstruction and from reduced systemic arterial compliance $[1,2] . Z_{\mathrm{va}}$ is a simple index that provides an estimate of the afterload imposed on the LV and is an important index of AS severity and predictor of LV dysfunction and outcomes [1,36-38]. $Z_{\mathrm{va}}$ is moderately elevated in patients with severe AS, and aortic valve replacement often only reduces the valvular component of afterload and has no effect on the arterial compliance of elderly patients, which may be due to other comorbidities, such as hypertension and atherosclerosis [38, 39]. Our study further demonstrated a correlation between 2D and 3D GLS and $Z_{\mathrm{va}}$ but no significant relationship between $\mathrm{Z}_{\mathrm{va}}$ and other deformation parameters. GLS also correlated with increasing LVEDV and E/e' ratio. The increase in LVEDV and $Z_{\mathrm{va}}$ represents a hemodynamic load that markedly increases wall stress and results in depressed myocardial contractility [22].

Previous studies have reported conflicting results of comparisons of 2D and 3D speckle-tracking echocardiography measurements, possibly because of major differences in the study populations such as sample size and the severity of AS, as well as methodology such as software used for measurement of strain [19, 40-43]. One prior study showed that $3 \mathrm{D}$ was not superior to $2 \mathrm{D}$ in measuring any of the three components of LV deformation [12]. Our study showed a modest agreement between $2 \mathrm{D}$ and $3 \mathrm{D}$ GLS and a poor agreement among other parameters. There was also a similar weak correlation between $2 \mathrm{D}$ and $3 \mathrm{D}$ GLS and $Z_{v a}$.

Theoretically, 3D imaging should be more accurate as it can overcome well-known limitations of 2D imaging by avoiding foreshortened apical views, providing a more complete picture of myocardial deformation in three dimensions, and reducing out-of-plane motion, which may affect the accuracy of LV strain and twist measurements. However, the lower temporal and spatial resolutions of 3D images are potential limitations that could adversely affect the accuracy of 3D measurements acquired at the lower frame rates [42, 43]. Nevertheless, our 3D measurements were still able to capture the pattern of myocardial deformation found in patients with severe AS observed on 2D, in which GLS and GRS were reduced and accompanied by an increase in GCS, apical rotation, and twist.

\section{Limitations}

Our study had several limitations worth considering. First, it was a single-center observational study, which may reduce the generalizability of the results. However, the prospective design of the study allowed for more precise patient selection and more comprehensive data collection that would not have been possible with a retrospective design. Second, given the elderly cohort of patients with severe AS, we were unable to recruit similar healthy ageand sex-matched subjects for comparison. Nevertheless, we used, to our knowledge, the best available reference values that have been previously published in literature for comparison including two large meta-analyses of $2 \mathrm{D}$ and 3D global strain. Third, our patients had pertinent comorbidities such as coronary artery disease, which could theoretically influence myocardial deformation. However, it would not be possible to fully account for all comorbidities that could affect strain in these patients. Our cohort therefore reflects a real world population of patients with severe AS with comorbid conditions. Fourth, we did not validate the deformation measurements against reference standards such as tagged magnetic resonance imaging or sonomicrometry. Furthermore, the relatively low frame rate of real-time 3D echocardiographic imaging could potentially lead to underestimating strain values. As well, the relatively high body mass index in our cohort may have led to poor image quality. Nevertheless, the similar findings obtained on both $2 \mathrm{D}$ and $3 \mathrm{D}$ provided a degree of 
quality assurance. Finally, it may not be possible to extrapolate our exact measurements to other ultrasound machine systems or 3D speckle tracking software, although we suspect that the pattern of deformation abnormalities observed may still be consistent.

\section{Conclusions}

In patients with severe AS, GLS and GRS are reduced while GCS, basal rotation, and twist are increased, presumably to maintain normal cardiac output and LVEF. These findings were shown by both $2 \mathrm{D}$ and $3 \mathrm{D}$ speckletracking echocardiography. Reductions in GLS were shown to correlate with measures of increased preload and afterload. Our study provided the most comprehensive $2 \mathrm{D}$ and $3 \mathrm{D}$ characterization of myocardial deformation to date in patients with severe AS and preserved LVEF.

\section{Abbreviations}

2D: 2-dimensional; 3D: 3-dimensional; AS: Aortic stenosis; CCC: Concordance correlation coefficient; E/e': Ratio of the early mitral inflow velocity to early mitral annular tissue Doppler velocity; EAE: Effective arterial elastance; EF: Ejection fraction; GCS: Global circumferential strain; GLS: Global longitudinal strain; GRS: Global radial strain; ICC: Intraclass correlation coefficient; LV: Left ventricular; LVEDV: Left ventricular end-diastolic volume; LVEF: Left ventricular ejection fraction; $M G_{n e t}$ : Mean net pressure gradient; SAP: Systolic arterial pressure; SV: Stroke volume; SVI: Stroke volume index; SVR: Systemic vascular resistance; SVRI: Systemic vascular resistance index; TAC: Total arterial compliance; TAS: Total arterial stiffness; Twist max: Peak systolic twist; $Z_{\text {va: }}$ Valvulo-arterial impedance

\section{Acknowledgements}

Not Applicable.

\section{Authors' contributions}

Conception and design of the study: XB, VTN, HRV. Acquisition of data or analysis and interpretation of data: JJT, LFN, KLG, AP, HVS. Drafting the article or revising it critically for important intellectual content: HRV, XB, MCC, SVP, PAP, HMS, DFY. All authors read and approved the final manuscript.

\section{Funding}

This research did not receive any grants from funding agencies in the public, commercial, or not-for-profit sectors.

\section{Availability of data and materials}

Data are available from the corresponding author on reasonable request.

\section{Ethics approval and consent to participate}

This study was approved by the Mayo Clinic Institutional Review Board, and all patients gave informed written consent to participate anonymously.

\section{Consent for publication}

Not applicable.

\section{Competing interests}

The authors declare that they have no competing interests.

\section{Author details}

'Department of Cardiovascular Diseases, Mayo Clinic, 200 First St SW, Rochester, MN 55905, USA. ²Department of Ultrasound, Tongji Hospital, Tongji Medical College, Huazhong University of Science and Technology, Wuhan, China. ${ }^{3}$ Faculty of Medicine, Jordan University of Science and Technology, Irbid 22110, Jordan.
Received: 22 July 2019 Accepted: 9 January 2020

Published online: 30 January 2020

\section{References}

1. Briand M, Dumesnil JG, Kadem L, et al. Reduced systemic arterial compliance impacts significantly on left ventricular afterload and function in aortic stenosis: implications for diagnosis and treatment. J Am Coll Cardiol. 2005;46:291-8.

2. Garcia D, Barenbrug PJ, Pibarot P, et al. A ventricular-vascular coupling model in presence of aortic stenosis. Am J Physiol Heart Circ Physiol. 2005; 288:H1874-84

3. Dusenbery SM, Lunze Fl, Jerosch-Herold M, et al. Left ventricular strain and myocardial fibrosis in congenital aortic stenosis. Am J Cardiol. 2015;116: $1257-62$.

4. Weidemann F, Herrmann S, Stork S, et al. Impact of myocardial fibrosis in patients with symptomatic severe aortic stenosis. Circulation. 2009;120:57784.

5. Delgado V, Tops LF, van Bommel RJ, et al. Strain analysis in patients with severe aortic stenosis and preserved left ventricular ejection fraction undergoing surgical valve replacement. Eur Heart J. 2009;30:3037-47.

6. Deng YB, Liu R, WU YH, Xiong L, Liu YN. Evaluation of short-axis and longaxis myocardial function with two-dimensional strain echocardiography in patients with different degrees of coronary artery stenosis. Ultrasound Med Biol. 2010;36:227-33.

7. van Dalen BM, Tzikas A, Soliman Ol, et al. Left ventricular twist and untwist in aortic stenosis. Int J Cardiol. 2011;148:319-24.

8. Ng AC, Delgado V, Bertini M, et al. Alterations in multidirectional myocardial functions in patients with aortic stenosis and preserved ejection fraction: a two-dimensional speckle tracking analysis. Eur Heart J. 2011;32:1542-50.

9. Miyazaki S, Daimon M, Miyazaki T, et al. Global longitudinal strain in relation to the severity of aortic stenosis: a two-dimensional speckle-tracking study. Echocardiography. 2011;28:703-8.

10. Carasso S, Cohen C, Mutlak D, et al. Relation of myocardial mechanics in severe aortic stenosis to left ventricular ejection fraction and response to aortic valve replacement. Am J Cardiol. 2011;107:1052-7.

11. Meimoun P, Elmkies F, Benali T, et al. Assessment of left ventricular twist mechanics by two-dimensional strain in severe aortic stenosis with preserved ejection fraction. Ann Cardiol Angeiol. 2011;60:259-66.

12. Altman M, Bergerot $C$, Aussoleil $A$, Davidsen ES, Sibellas F, Ovize $M$, et al. Assessment of left ventricular systolic function by deformation imaging derived from speckle tracking: a comparison between $2 \mathrm{D}$ and $3 \mathrm{D}$ echo modalities. Eur Heart I Cardiovasc Imaging. 2014;15:316-23.

13. Kusunose K, Goodman A, Parikh R, Barr T, Agarwal S, Popovic ZB, et al. Incremental prognostic value of left ventricular global longitudinal strain in patients with aortic stenosis and preserved ejection fraction. Circ Cardiovasc Imaging. 2014;7:938-45.

14. Sato K, Seo Y, Ishizu T, Takeuchi M, Izumo M, Suzuki K, et al. Prognostic value of global longitudinal strain in paradoxical low-flow, low-gradient severe aortic stenosis with preserved ejection fraction. Circ J. 2014;78:27509.

15. Musa TA, Uddin A, Swoboda PP, Fairbairn TA, Dobson LE, Singh A, et al. Cardiovascular magnetic resonance evaluation of symptomatic severe aortic stenosis: association of circumferential myocardial strain and mortality. J Cardiovasc Magn Reson. 2017;19:13.

16. Vollema EM, Sugimoto T, Shen M, et al. Association of Left Ventricular Global Longitudinal Strain with asymptomatic severe aortic stenosis: natural course and prognostic value. JAMA Cardiol. 2008;3:839-47.

17. Eidet J, Dahle G, Bugge JF, Bendz B, Rein KA, Aaberge L, et al. Intraoperative improvement in left ventricular peak systolic velocity predicts better shortterm outcome after transcatheter aortic valve implantation. Interact Cardiovasc Thorac Surg. 2016;22:5-12

18. Nagata Y, Takeuchi M, Wu VC, et al. Prognostic value of LV deformation parameters using $2 \mathrm{D}$ and $3 \mathrm{D}$ speckle-tracking echocardiography in asymptomatic patients with severe aortic stenosis and preserved LV ejection fraction. JACC Cardiovasc Imaging. 2015;8:235-45.

19. Li CM, Li C, Bai WJ, Zhang XL, Tang H, Qing Z, et al. Value of threedimensional speckle-tracking in detecting left ventricular dysfunction in patients with aortic valvular diseases. J Am Soc Echocardiogr. 2013;26: 1245-52.

20. Lang RM, Badano LP, Mor-Avi V, Afilalo J, Armstrong A, Ernande L, et al. Recommendations for cardiac chamber quantification by echocardiography 
in adults: an update from the American Society of Echocardiography and the European Association of Cardiovascular Imaging. J Am Soc Echocardiogr. 2015;28:1-39.e14.

21. Ye Z, Coutinho T, Pellikka PA, Villarraga HR, Borlaug BA, Kullo IJ. Associations of alterations in pulsatile arterial load with left ventricular longitudinal strain. Am J Hypertens. 2015;28:1325-31.

22. Maréchaux S, Carpentier E, Six-Carpentier M, Asseman P, LeJemtel TH, Jude $B$, et al. Impact of valvuloarterial impedance on left ventricular longitudinal deformation in patients with aortic valve stenosis and preserved ejection fraction. Arch Cardiovasc Dis. 2010;103:227-35.

23. Yingchoncharoen T, Agarwal S, Popovic ZB, Marwick TH. Normal ranges of left ventricular strain: a meta-analysis. J Am Soc Echocardiogr. 2013; 26:185-91.

24. Andrade J, Cortez LD, Campos O, et al. Left ventricular twist: comparison between two- and three-dimensional speckle-tracking echocardiography in healthy volunteers. Eur J Echocardiogr. 2011;12:76-9.

25. Truong VT, Phan HT, Pham KNP, et al. Normal ranges of left ventricular strain by three-dimensional speckle-tracking echocardiography in adults: a systematic review and meta-analysis. J Am Soc Echocardiogr. 2019;32(12): 1586-97.

26. Amzulescu MS, De Craene $M$, Langet $H$, et al. Myocardial strain imaging: review of general principles, validation, and sources of discrepancies. Eur Heart J Cardiovasc Imaging. 2019;20:605-19.

27. Mizuguchi Y, Oishi Y, Miyoshi H, luchi A, Nagase N, Oki T. The functional role of longitudinal, circumferential, and radial myocardial deformation for regulating the early impairment of left ventricular contraction and relaxation in patients with cardiovascular risk factors: a study with twodimensional strain imaging. J Am Soc Echocardiogr. 2008;21:1138-44.

28. Fung MJ, Thomas L, Leung DY. Alterations in layer-specific left ventricular global longitudinal and circumferential strain in patients with aortic stenosis: a comparison of aortic valve replacement versus conservative management over a 12-month period. J Am Soc Echocardiogr. 2019;32:92-101.

29. Poulin F, Carasso S, Hrorlick EM, et al. Recovery of left ventricular mechanics after transcatheter aortic valve implantation: effects of baseline ventricular function and postprocedural aortic regurgitation. J Am Soc Echocardiogr. 2014;27:1133-42

30. Carasso S, Cohen O, Mutlak D, et al. Differential effects of afterload on left ventricular long- and short-axis function: insights from a clinical model of patients with aortic valve stenosis undergoing aortic valve replacement. Am Heart J. 2009;158:540-5.

31. Popescu BA, Calin A, Beladan CC, et al. Left ventricular torsional dynamics in aortic stenosis: relationship between left ventricular untwisting and filling pressures. A two-dimensional speckle tracking study. Eur J Echocardiogr. 2010:11:406-13.

32. Notomi Y, Lysyansky P, Setser RM, Shiota T, Popovic ZB, Martin-Miklovic MG, et al. Measurement of ventricular torsion by two-dimensional ultrasound speckle tracking imaging. J Am Coll Cardiol. 2005;45:2034-41.

33. Helle-Valle T, Crosby J, Edvardsen T, Lyseggen E, Amundsen BH, Smith HJ, et al. New noninvasive method for assessment of left ventricular rotation: speckle tracking echocardiography. Circulation. 2005;112:3149-56.

34. Sallin EA. Fiber orientation and ejection fraction in the human left ventricle. Biophys J. 1969:9:954-64

35. Kauer F, Geleijnse ML, van Dalen BM. Role of left ventricular twist mechanics in cardiomyopathies, dance of the helices. World J Cardiol. 2015;7:476-82.

36. Zito C, Salvia J, Cusma-Piccione M, Antonini-Canterin F, Lentini S, Oreto G, et al. Prognostic significance of valvuloarterial impedance and left ventricular longitudinal function in asymptomatic severe aortic stenosis involving three-cuspid valves. Am J Cardiol. 2011;108(10):1463-9 Epub 2011 Aug 25 .

37. Magne J, Mohty D, Boulogne C, Deltreuil M, Cassat C, Echahidi N, et al. Prognostic impact of global left ventricular hemodynamic afterload in severe aortic stenosis with preserved ejection fraction. Int J Cardiol. 2015; 180:158-64.

38. Hachicha Z, Dumesnil JG, Pibarot P. Usefulness of the valvuloarterial impedance to predict adverse outcome in asymptomatic aortic stenosis. J Am Coll Cardiol. 2009;54:1003-11.

39. Pagel PS, Schroeder AR, De Vry DJ, Hudetz JA. Aortic valve replacement reduces valvuloarterial impedance but does not affect systemic arterial compliance in elderly men with degenerative calcific trileaflet aortic valve stenosis. J Cardiothorac Vasc Anesth. 2014;28:1540-4.
40. Abduch MC, Alencar AM, Mathias W Jr, Vieira ML. Cardiac mechanics evaluated by speckle tracking echocardiography. Arq Bras Cardiol. 2014;102: $403-12$.

41. Stefani L, De Luca A, Toncelli L, Pedrizzetti G, Galanti G. 3D strain helps relating $\mathrm{LV}$ function to LV and structure in athletes. Cardiovasc Ultrasound. 2014;12:33.

42. Yodwut $C$, Weinert $L$, Klas $B$, Lang RM, Mor-Avi V. Effects of frame rate on three-dimensional speckle-tracking-based measurements of myocardial deformation. J Am Soc Echocardiogr. 2012;25:978-85.

43. Kaku K, Takeuchi M, Tsang W, et al. Age-related normal range of left ventricular strain and torsion using three-dimensional speckle-tracking echocardiography. J Am Soc Echocardiogr. 2014;27:55-64.

\section{Publisher's Note}

Springer Nature remains neutral with regard to jurisdictional claims in published maps and institutional affiliations.
Ready to submit your research? Choose BMC and benefit from:

- fast, convenient online submission

- thorough peer review by experienced researchers in your field

- rapid publication on acceptance

- support for research data, including large and complex data types

- gold Open Access which fosters wider collaboration and increased citations

- maximum visibility for your research: over $100 \mathrm{M}$ website views per year

At BMC, research is always in progress.

Learn more biomedcentral.com/submissions 